\title{
Dens agenesis and cervical vertebral malformation in a Labrador Retriever puppy
}

\author{
This article was published in the following Dove Press journal: \\ Veterinary Medicine: Research and Reports \\ 18 December 2014 \\ Number of times this article has been viewed
}

\author{
Elisa N Salas' \\ Henry E Cerny ${ }^{2}$ \\ Seth P Harris' \\ 'Institute of Agriculture and Natural \\ Resources, School of Veterinary \\ Medicine and Biomedical Sciences, \\ University of Nebraska-Lincoln, \\ Lincoln, NE, USA; ${ }^{2}$ Yankee Hill \\ Veterinary Hospital, Lincoln, NE, USA
}

Correspondence: Seth P Harris Institute of Agriculture and Natural Resources, School of Veterinary Medicine and Biomedical Sciences, University of Nebraska-Lincoln, PO Box 830905, East Campus Loop and Fair Street, Lincoln, NE 68583-0905, USA

Tel +l 4024728542

Email sharris4@unl.edu

\begin{abstract}
Cervical vertebral malformations can cause acute or progressive pain, paralysis, and potentially death. Herein we present a case report of dens agenesis; cervical vertebral malformations of $\mathrm{C} 1, \mathrm{C} 2, \mathrm{C} 6$, and $\mathrm{C} 7$; subluxation of $\mathrm{C} 1$ and $\mathrm{C} 2$ and $\mathrm{C} 4$ and $\mathrm{C} 5$; and associated degenerative myelopathy in a 5-month-old female Labrador Retriever puppy. We additionally review current knowledge regarding pathogenesis and treatment.
\end{abstract}

Keywords: atlantoaxial subluxation, cervical vertebral malformation, dog, dens agenesis, myelopathy

\section{History}

A 5-month-old silver female Labrador Retriever was presented for nightly episodes of whining and restlessness, which the owners attributed to pain. The puppy was otherwise healthy with no prior medical conditions.

\section{Clinical and gross findings}

Physical examination revealed a bright, alert, and responsive patient with pain on palpation of the dorsal cervical and thoracic region of the spinal column. Maxillary brachygnathism and mandibular malposition of incisors 301 and 401 were noted. Complete blood count was unremarkable. Radiographs of the spinal column were performed under sedation. Radiographs revealed osseous malformations confined to the cervical spinal column. These findings included subluxation of the atlantoaxial articulation and shortening of the dorsal spinous process of the axis (Figure 1A and $\mathrm{B}$ ), subluxation of $\mathrm{C} 4-\mathrm{C} 5$ articulation, and lack of rectangular shape of $\mathrm{C} 6$ and $\mathrm{C} 7$ vertebral bodies (Figure 1A). Conservative analgesic therapy was elected and the patient was discharged with oral carprofen at $2 \mathrm{mg} / \mathrm{kg}$ and tramadol hydrochloride at $2.5 \mathrm{mg} / \mathrm{kg}$ every 12 hours. Twenty-eight days later, due to increasing unmitigated pain, the owners elected euthanasia and postmortem evaluation.

Necropsy confirmed the maxillary and mandibular findings. The cervical spinal cord and visceral organs were fixed in formalin. The spinal column and skull were boiled and cleaned to better visualize the skeletal malformations. Skull abnormalities found were incomplete fusion of the ventral aspect of the foramen magnum and a small keyhole defect within the occipital bone. Atlas malformations included bilaterally misshapen cranial articular processes, elongation of these processes into the ventral arch, bilaterally symmetric transverse folds of the cranial articular foveae, an approximately $4 \mathrm{~mm}$ long fissure of the caudal vertebral arch, and flattening of the caudal articular 


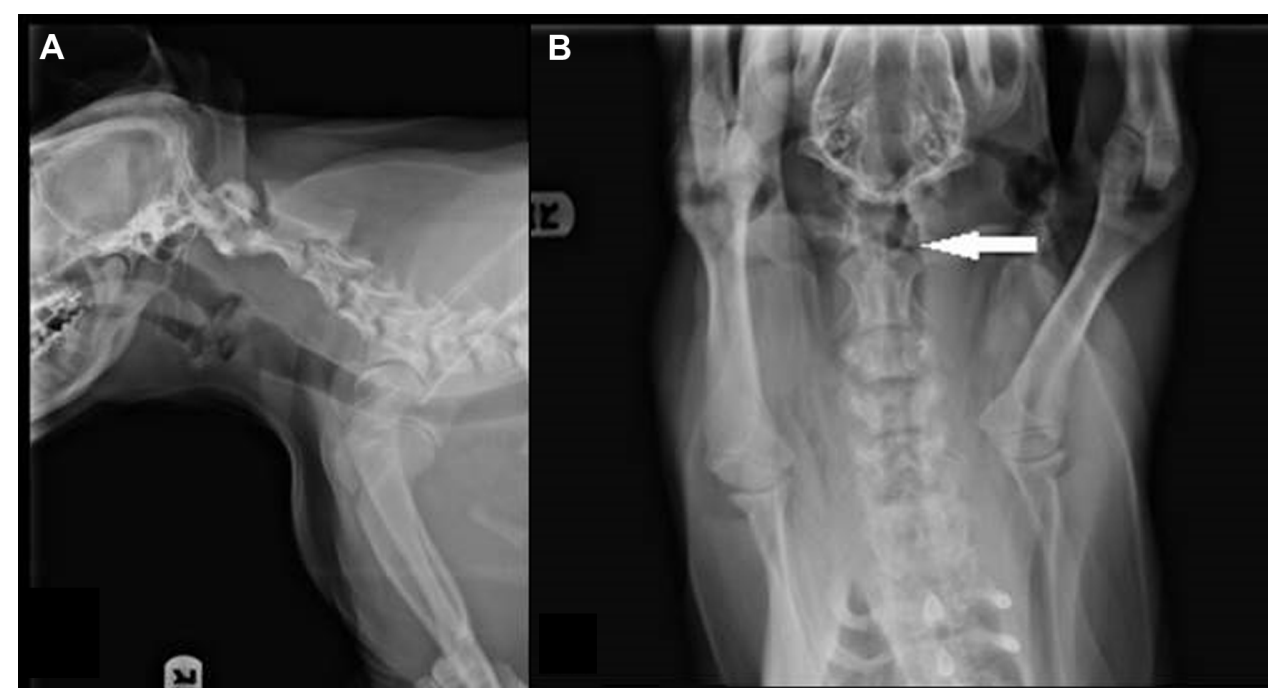

Figure I Radiographs of the head and neck. Left to right lateral radiographs of the neck (A) reveal atlantoaxial subluxation and shortened dens of C2 (white arrow). Additionally, C4-C5 junction is subluxated and vertebral bodies of C6 and C7 are not rectangular. (B) Ventral-dorsal radiographs of the cervical vertebrae highlight the separation of $\mathrm{Cl}$ and $\mathrm{C2}$ (white arrow).

processes (Figure 2A and B). On the caudal tubercle of the atlas, there was a caudal flattened semicircular, $15 \mathrm{~mm}$ diameter callus, which apposed a $12 \mathrm{~mm}$ long spade-shaped callus on the cranial aspect of the spinous process of the axis (Figures 2A and 3B). Other changes in the axis included lack of the dens and bilateral flattening of the cranial articular processes (Figure 3A). All cervical and thoracic vertebral bodies examined had incomplete fusion of the ventral aspect of the vertebral foramina. Gaps of approximately 3-4 mm diameter with a depth $<1 \mathrm{~mm}$ ran the length of the vertebrae.

\section{Histopathologic findings}

Histologic evaluation was performed on sections of caudal brainstem, spinal cord segments from the atlas and atlantoaxial junction, and the visceral organs. Sections bordering the caudal brainstem and at the junction of $\mathrm{C} 1$ and the foramen magnum had few dilated axon sheathes and few spheroids; these lesions were randomly scattered. The section from the junction of $\mathrm{C} 1$ and $\mathrm{C} 2$ contained several spheroids and dilated axon sheaths (Figure 4). The white matter contained a few medium-sized, poorly circumscribed areas of rarefaction and infiltration by microglia. The associated blood vessels were lined by hypertrophied endothelial cells and contained frequent marginating monocytes. Many spheroids were associated with this area of gliosis. Additionally, in the section from $\mathrm{C} 1$ to $\mathrm{C} 2$, the vacuoles were most prominent bilaterally within the dorsal and dorsolateral funiculi. The sections from the viscera did not have clinically significant lesions.

\section{Morphologic diagnoses}

1. Dens agenesis with atlantoaxial subluxation and multiple cervical and thoracic vertebral osseous defects

2. Degenerative myelopathy, multifocal, chronic, mild.

\section{Discussion}

The primary lesion in this case was the agenesis of the dens, resulting in instability of the atlantoaxial articulation. This caused the clinical signs of pain due to spinal cord compression. Agenesis of the dens has classically been attributed to trauma with secondary ischemia and necrosis, or due to congenital lack of the ossification center. ${ }^{1}$ In this case we suspect that this lesion developed due to a congenital

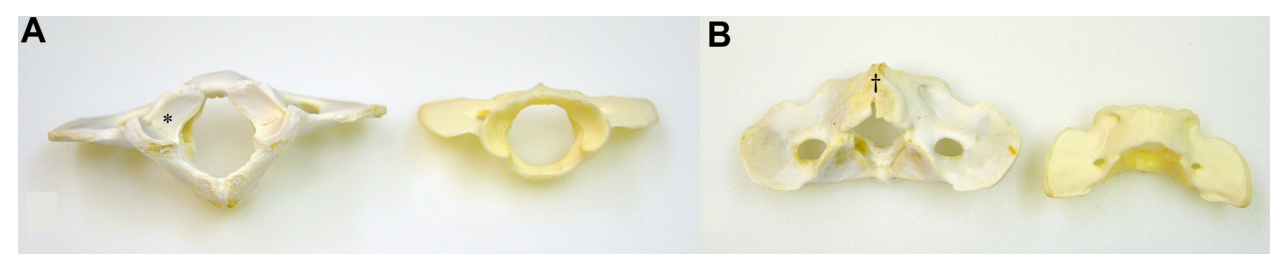

Figure 2 Photographs of the misshapen atlas (left side) and of a control atlas (right side), caudal aspect. The cranial surface (A) shows bilaterally misshapen cranial articular foveae with symmetric transverse folds within the articular surface $(*)$. An approximately $4 \mathrm{~mm}$ long fissure (†) of the caudal vertebral arch is present (B) within a bone callus. 
A

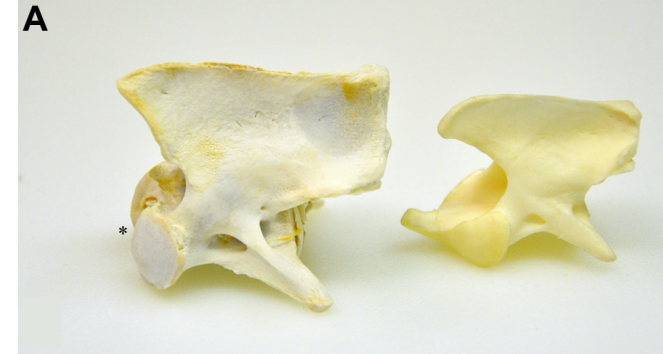

B

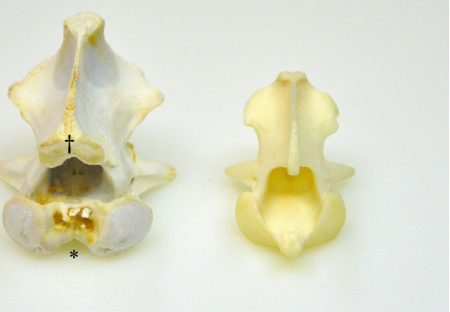

Figure 3 Photographs of the misshapen axis (left) and of a control axis (right), cranial aspect. The lack of a dens $\left({ }^{*}\right)$ and bilaterally misshapen and flattened cranial articular processes are featured (A and B). The spinous process has a $12 \mathrm{~mm}$ long spade-shaped callus ( $\dagger$ ) on the cranial aspect (B).

lack of the ossification center caused by a primary ventral midline fusion defect. This suspicion is based on the young age of the dog and the presence of other midline fusion defects (eg, occipital bone malformation and the incomplete fusion of the vertebral bodies within the ventral aspect of the vertebral canals).

Although a common condition, pathogenesis of dens agenesis is unknown in both humans and animals. First described in 1933, it was termed os odontoideum syndrome. ${ }^{2}$ As in dogs, hypothesized parthenogeneses include either lack for formation of traumatization. ${ }^{3}$ In humans, ossification of the dens begins by 3 years of age and is complete late in life, leaving this process vulnerable to injury. ${ }^{3}$ In the dog, dens formation begins much earlier at approximately 30 days of age in utero, and ossification in the dog is complete as early as 6 weeks of age. ${ }^{4,5}$ Thus, our patient's defect is believed to be congenital rather than traumatic. In dogs, not all dens agenesis cases progress, as evidenced by a Rottweiler aged 9.5 years who first presented with signs at 6 months of age and lacked worsening and was euthanized due to a recurrent

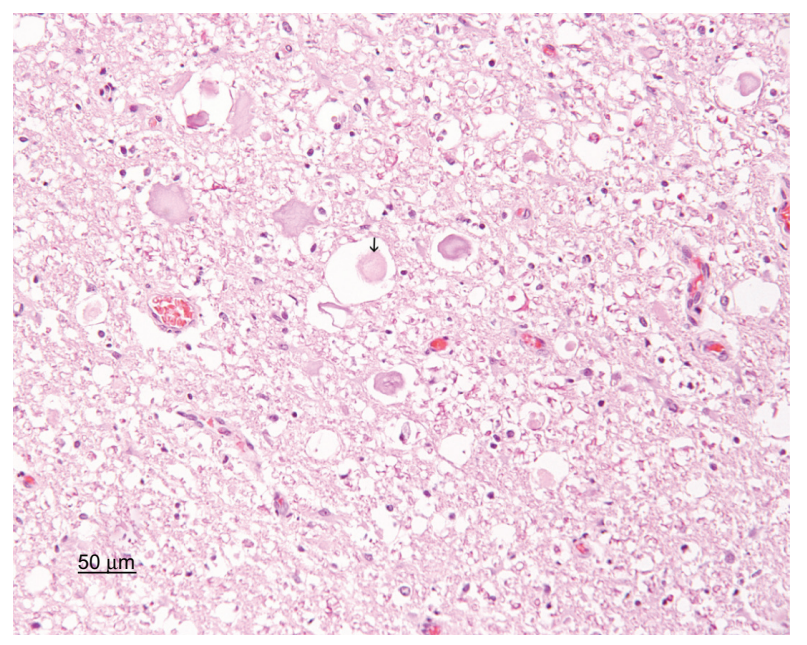

Figure 4 Photomicrograph of the spinal cord taken at $\mathrm{Cl}$. Scattered small to medium spheroids and axonal swelling are indicators of axonal degeneration (arrow). Artifactual spongiosis is present. Hematoxylin and eosin stain; bar $=50 \mu \mathrm{m}$. oral sarcoma. ${ }^{6}$ Familial mode of inheritance is recognized in the Arabian horse (Watson), but, to date, no genetic marker has been identified. ${ }^{7}$ With sequencing of the dog genome, analysis of genetics of affected patients may hold promise of finding a genetic basis of this disease.

During the initial clinical evaluation, a number of possible differential diagnoses were considered, including Chiari-like malformation, occipitoatlantoaxial malformation, and atlantoaxial instability or subluxation. Chiari-like malformation is a congenital lesion consisting of supraoccipital hypoplasia, which causes a decreased diameter of the foramen magnum. ${ }^{8}$ When secondary lesions are present, they can include cerebellar herniation, compression of the medulla, and destruction of the dorsal subarachnoid space. Secondary impairment in cerebrospinal fluid can occur, with resulting syringomyelia or hydromyelia. ${ }^{9}$ Cavalier King Charles Spaniels and Griffon Bruxellois dogs are overrepresented. ${ }^{10}$ Cavalier King Charles Spaniels have a suspected autosomal recessive gene defect with incomplete penetrance. ${ }^{8}$

Occipitoatlantoaxial malformation typically arises due to bilateral fusion of the atlas to the occipital bones of the skull with dens hypoplasia. ${ }^{1}$ This can cause secondary changes such as narrowing of the foramen magnum with compression of the brainstem or cervical spinal cord. Detection of this lesion can be made with palpation, imaging studies, or necropsy.

Atlantoaxial instability, or subluxation, is an umbrella term that includes nonunion of the dens with axis, aplasia or hypoplasia of the dens, or lack of the transverse ligament of the axis. ${ }^{2,11}$ It is more commonly reported in toy breed dogs, with Miniature and Toy Poodles, Chihuahuas, Pekingese, Pomeranian, and Yorkshire Terrier dogs being predisposed. ${ }^{12,13}$ There are a few reports of this condition in large breed dogs, cats, lambs, horses, and a camel. . $^{6,714-16}$ Clinical signs include cervical pain and guarding, upper motor neuron deficits of all four limbs with progression to tetraperesis, or, rarely, paralysis of all four limbs with 
worsening of signs upon flexion of the neck. Primary lesions of the dens, such as aplasia and hypoplasia, occur more frequently than absence of the transverse ligament. ${ }^{17}$ Also reported are morphologic abnormalities of $\mathrm{C} 1$ and $\mathrm{C} 2$. Clinical signs can be attributed to spinal cord compression with resultant syringomyelia, axonopathy, neuronal necrosis, and edema. Radiography can reveal signs of subluxation but may not identify the primary lesion. ${ }^{18}$ Myelography can confirm a subluxation as well and possibly show syringomyelia. However, magnetic resonance imaging can be diagnostic antemortem and has the added benefit of avoiding postprocedural seizures seen in affected patients with myelography.

The patient also had deviation of the $\mathrm{C} 4-\mathrm{C} 5$ junction or malformation of $\mathrm{C} 6$ and $\mathrm{C} 7$ vertebral bodies, which did not manifest clinically or during physical examination. This was confirmed by gross examination of the body. Histology was not pursued of the caudal spinal cord. Cervical vertebral malformations have been reported in Doberman Pinschers, Basset Hounds, and Bernese Mountain Dogs. ${ }^{19-22}$ Pathogenesis is associated with congenital or prenatal conditions in the Doberman Pinscher. However, genetic markers have yet to be defined (Rusbridge et al). Findings can include loss of rectangularity of vertebral bodies, stenosis of the foramina of the bodies, intervertebral disc disease, joint capsule proliferation, spinous process cranial deviation and enlargement, articular process osteoarthritis, and hypertrophy of the ligamentum most frequently at the $\mathrm{C} 4-\mathrm{C} 5$ junction. A literature search of caudal cervical vertebral malformation failed to reveal concurrent atlantoaxial malformations. Thus, definitive pathogenesis of these two conditions is unknown. However, we speculate that a heritable defect is likely with a nondominant pathogenesis due to lack of affected siblings. Although histological evaluation of the spinal cord alone would not have revealed a specific etiology, the skeletal malformations observed indicated that compressive forces from skeletal malformations caused the degenerative changes. Microscopic examination also served to eliminate other causes of spinal cord disease, such as primary inflammatory, degenerative, or neoplastic conditions.

The goal of treatment of atlantoaxial instability is stabilization and resolution of spinal cord compression. ${ }^{12,23,24}$ Conservative management is indicated for patients with mild clinical signs, acute signs, or dogs who have incomplete physeal ossification. ${ }^{23}$ Therapy includes immobilization of the head and neck positioned in extension with a cervical splint (ventrally reinforced), corticosteroids, and exercise restriction for a period of 6 weeks with a reported 50\%-63\% success rate. ${ }^{23}$ Multiple surgical techniques have been performed and include dorsal atlantoaxial stabilization, left hemilaminectomy, ventral stabilization, transarticular fixation with pins, lag screw fixation, and a modified ventral fixation. ${ }^{12,13,24}$ Surgical fixation can halt progression or allow for reversal of clinical signs. The most common complications include hardware migration, failure of fixation with subluxation, and intraoperative brain stem trauma.

Treatment of cervical vertebral malformations is reserved for patients with clinical signs associated with myelopathy. Such myelopathy can cause spinal cord compressive lesions or intervertebral disc instability with subsequent extrusion of disc material. These conditions are corrected with ventral slot decompression. ${ }^{19}$

Antemortem, the patient displayed pain but lacked neurologic deficits. As pain management therapy had failed to provide satisfactory amelioration of the clinical signs, and calluses had developed on the articular facets of the atlas and axis due to chronic instability, it is questionable whether conservative management would have been successful long term. As spinal cord compression resulted only in pain rather than neurologic deficits, the patient may have been amenable to surgical stabilization.

\section{Disclosure}

No outside financial support was provided.

\section{References}

1. Watson AG, Evans HE, de Lahunta A. Ossification of the atlas-axis complex in the dog. Anat Histol Embryol. 1986;15:122-138.

2. Flemming C, Hodson CJ. Os odontoideum; a congenital abnormality of the axis; case report. J Bone Joint Surg Br. 1955;37-B(4):622-623.

3. Cunningham DJ. Connection of the os odontoideum with the body of the axis vertebra. $J$ Anat Physiol. 1886;20(Pt 2):238-243.

4. Watson AG, de Lahunta A, Evans HE. Morphology and embryological interpretation of a congenital occipito-atlanto-axial malformation in a dog. Teratology. 1988;38(5):451-459.

5. Watson AG, Stewart JS. Postnatal ossification centers of the atlas and axis in Miniature Schnauzers. Am J Vet Res. 1990;51(2):264-268.

6. Patton K, Almes KM, de Lahunta A. Absence of the dens in a 9.5year-old Rottweiler with non-progressive clinical signs. Can Vet J. 2010;51:1007-1010.

7. Watson AG, Mayhew IG. Familial congenital occipitoatlantoaxial malformation (OAAM) in the Arabian horse. Spine. 1986;11(4): 334-339.

8. Rusbridge C, Knowler SP. Hereditary aspects of occipital bone hypoplasia and syringomyelia (Chiari type I malformation) in Cavalier King Charles Spaniels. Vet Rec. 2003;153(4):107-112.

9. Rusbridge C. Neurological diseases of the Cavalier King Charles Spaniel. J Small Anim Pract. 2005;46(6):265-272.

10. Rusbridge C, Knowler SP, Pieterse L, McFadyen AK. Chiari-like malformation in the Griffon Bruxellois. J Small Anim Pract. 2009;50(8): 386-393.

11. Geary JG, Oliver JE, Hoerlein BF. Atlanto axial subluxation in the canine. J Small Anim Pract. 1967;8(10):577-582. 
12. Denny HR, Gibbs C, Waterman A. Atlanto-axial subluxation in the dog: a review of thirty cases and an evaluation of treatment by lag screw fixation. J Small Anim Pract. 1988;29(1):37-47.

13. Thomas WB, Sorjonen DC, Simpson ST. Surgical management of atlantoaxial subluxation in 23 dogs. Vet Surg. 1991;20(6):409-412.

14. Shelton SB, Bellah J, Chrisman C, McMullen D. Hypoplasia of the odontoid process and secondary atlantoaxial luxation in a Siamese cat. Prog Vet Neuro. 1991;2:209-211.

15. Lakritz J, Barr BC, George LW, et al. Cervical and thoracic vertebral malformation ("weak neck") in Colombia lambs. J Vet Intern Med. 1995;9(6):393-398.

16. Sakamoto K, Kiupel M, Frank N, March PA. Vertebral malformation, syringomyelia, and ventricular septal defect in a dromedary camel (Camelius dromedarius). J Vet Diagn Invest. 2004;16(4):337-340.

17. Watson AG, de Lahunta A. Atlantoaxial subluxation and absence of transverse ligament of the atlas in a dog. $\mathrm{J} \mathrm{Am} \mathrm{Vet} \mathrm{Med} \mathrm{Assoc.}$ 1989;195(2):235-237.

18. Cerda-Gonzalez S, Dewey CW, Scrivani PV, Kline KL. Imaging features of atlanto-occipital overlapping in dogs. Vet Radiol Ultrasound. 2009;50(3):264-268.
19. Eagleson JS, Diaz J, Platt SR, et al. Cervical vertebral malformationmalarticulation syndrome in the Bernese Mountain Dog: clinical and magnetic resonance imaging features. J Small Anim Pract. 2009;50(4): 186-193.

20. da Costa RC, Parent JM, Partlow G, Dobson H, Holmberg DL, Lamarre J. Morphologic and morphometric magnetic resonance imaging features of Doberman Pinschers with and without clinical signs of cervical spondylomyelopathy. Am J Vet Res. 2006;67(9):1601-1612.

21. Trotter EJ, deLahunta A, Geary JC, Brasmer TH. Caudal cervical vertebral malformation-malarticulation in Great Danes and Doberman Pinschers. J Am Vet Med Assoc. 1976;168(10):917-930.

22. De Decker S, De Risio L, Lowrie M, et al. Cervical vertebral stenosis associated with a vertebral arch anomaly in the Basset Hound. $J$ Vet Intern Med. 2012;26(6):1374-1382.

23. Havig ME, Cornell KK, Hawthorne JC, McDonnell JJ, Selcer BA. Evaluation of nonsurgical treatment of atlantoaxial subluxation in dogs: 19 cases (1992-2001). J Am Vet Med Assoc. 2005;227(2):257-262.

24. Platt SR, Chambers JN, Cross A. A Modified ventral fixation for surgical management of atlantoaxial subluxation in 19 dogs. Vet Surg 2004;33(4):349-354.

\section{Publish your work in this journal}

Veterinary Medicine: Research and Reports is an international, peer-reviewed, open access journal publishing original research, case reports, editorials, reviews and commentaries on all areas of veterinary medicine. The manuscript management system is completely online and includes a very quick and fair peer-review system.

\section{Dovepress}

Visit http://www.dovepress.com/testimonials.php to read real quotes from published authors. 